ISSN : 2303-1514 | E-ISSN : 2598-5949

\title{
EXPECTATIONS OF ELEMENTARY SCHOOL TEACHERS TOWARD THE USE OF WEB-BASED APPLICATIONS IN ONLINE LEARNING DURING THE PANDEMIC
}

\author{
Linda Feni Haryati ${ }^{1}$, Arif Widodo ${ }^{2}$ \\ ${ }^{1,2}$ Program Studi Pendidikan Guru Sekolah Dasar, Universitas Mataram, Indonesia \\ Ilindafeni@unram.ac.id, ${ }^{2}$ arifwidodo@unram.ac.id
}

\section{EKSPEKTASI GURU SEKOLAH DASAR TERHADAP PENGGUNAAN APLIKASI BERBASIS WEB DALAM PEMBELAJARAN DARING DI ERA PANDEMI}

\begin{tabular}{|c|c|}
\hline ARTICLE HISTORY & ABSTRACT \\
\hline $\begin{array}{l}\text { Submitted: } \\
20 \text { Agustus } 2021 \\
20^{\text {th }} \text { August } 2021\end{array}$ & $\begin{array}{l}\text { Abstract: The media has a crucial role in online learning in the pandemic era. One of the } \\
\text { media that teachers need in online learning is a web-based application. This study aimed to } \\
\text { determine teacher expectations of the use of web-based applications in online learning. This } \\
\text { study was survey research conducted at one of the public elementary schools in Kabupaten } \\
\text { Lombok Barat. The survey was conducted on } 15 \text { primary school teachers. The results of the } \\
\text { study indicated that teachers were not familiar with web-based applications to facilitate online } \\
\text { learning. Only } 20 \% \text { of teachers were reliable with the use of web-based applications for } \\
\text { learning. Most teachers expected to receive training related to the use of web-based } \\
\text { applications. The application used was only limited to the WhatsApp Group. Teachers' ability } \\
\text { to use other web-based applications was still limited. At least } 80 \% \text { of teachers felt that they } \\
\text { needed special training in the use of web-based applications for the learning process and the } \\
\text { evaluation of students' learning outcomes. }\end{array}$ \\
\hline
\end{tabular}

Keywords: web applications, teacher expectations, online learning

Accepted:

26 September 2021

$26^{\text {th }}$ September 2021

Published:

28 Oktober 2021

$28^{\text {th }}$ October 2021

Abstrak: Media memiliki peranan yang sangat penting dalam pembelajaran daring di era pandemi. Salah satu media yang dibutuhkan guru dalam pembelajaran daring adalah aplikasi berbasis web. Penelitian ini bertujuan untuk mengetahui ekspektasi guru terhadap penggunaan aplikasi berbasis web dalam pembelajaran daring. Jenis penelitian yang digunakan adalah penelitian survei. Penelitian dilakukan pada salah satu sekolah dasar negeri di kabupaten Lombok Barat. Survei dilakukan terhadap 15 guru sekolah dasar. Hasil penelitian menunjukkan bahwa guru belum banyak mengenal aplikasi berbasis web untuk memudahkan pembelajaran daring. Hanya ada $20 \%$ guru yang telah handal dengan penggunaan aplikasi berbasis web dalam pembelajaran. Sebagian besar guru berharap agar mendapatkan pelatihan terkait dengan penggunaan aplikasi berbasis web. Aplikasi yang digunakan hanya sebatas WhatsApp Group. Kemampuan guru dalam penggunaan aplikasi berbasis web yang lain masih terbatas. Setidaknya ada $80 \%$ guru yang merasa membutuhkan pelatihan khusus dalam pemanfaatan aplikasi berbasis web untuk proses pembelajaran maupun evaluasi hasil belajar siswa.

Kata Kunci: aplikasi web, ekspektasi guru, pembelajaran daring

\section{CITATION}

Haryati, L. F., \& Widodo, A. (2021). Expectations of Elementary School Teachers toward the Use of Web-Based Applications in Online Learning During the Pandemic. Primary: Jurnal Pendidikan Guru Sekolah Dasar, 10 (5), 1234-1241. DOI: http://dx.doi.org/10.33578/jpfkip.v10i5.8528.

\section{PENDAHULUAN}

Pembelajaran daring merupakan salah satu solusi dalam mengatasi problematika pembelajaran di era pandemi. Pembelajaran daring sebagai salah satu jenis pembelajaran jarak jauh dipandang sebagai model pembelajaran yang paling tepat untuk diterapkan selama pandemi (Abidah, Hidaayatullaah, Simamora, Fehabutar, \& Mutakinati, 2020). Model pembelajaran daring 
relatif lebih fleksibel dari segi tempat dan waktu. Pembelajaran dapat dilakukan di mana saja tanpa terbatas ruang dan waktu (Pradana, 2016). Terdapat banyak kemudahan yang ditawarkan dalam pembelajaran daring. Selain fleksibel dari segi ruang dan waktu pembelajaran daring memiliki berbagai kelebihan dibanding dengan pembelajaran tatap muka. Salah satu diantaranya adalah proses pembelajaran dapat direcord. Dengan adanya recording ini memungkinkan materi pelajaran dapat diulang-ulang. Hal ini sangat bermanfaat jika siswa ingin mengulang kembali materi pelajaran atau untuk memperjelas pemahaman terkait dengan materi yang disampaikan guru.

Kemudahan yang ditawarkan dalam pembelajaran daring ternyata tidak dapat dirasakan oleh semua siswa. Meskipun dari segi waktu dan tempat sangat fleksibel tetapi dari segi atmosfir pembelajaran belum terbentuk dengan baik (Widodo \& Nursaptini, 2020). Artinya adalah banyak siswa yang tidak merasa belajar walaupun telah belajar dengan online. Selain itu lingkungan belajar siswa di rumah banyak mengalami gangguan sehingga mengurangi konsentrasi siswa. Tidak hanya siswa, guru dalam pembelajaran daring juga mengalami banyak hambatan. Perubahan model pembelajaran dari pembelajaran langsung ke pembelajaran jarak jauh membutuhkan banyak penyesuaian. Salah satunya adalah kemampuan guru dalam memfasilitasi pembelajaran. Guru dituntut untuk mampu memberikan layanan belajar secara maksimal dalam kondisi yang tidak normal (Komalawati, 2020). Pembelajaran dikatakan tidak normal dikarenakan pembelajaran dilakukan tidak seperti biasanya. Pembelajaran jarak jauh pada era ini dilakukan dalam keadaan darurat. Persiapan dan kesiapan guru dan siswa dalam menghadapi model pembelajaran ini dapat dikatakan belum maksimal. Masih banyak hal yang harus diperhatikan sebagai bahan evaluasi pelaksanaan pembelajaran jarak jauh di era pandemi.
Pasca diterapkannya pembelajaran daring bukan berarti masalah pembelajaran di era pandemi telah selesai. Justru masalahmasalah baru banyak ditemukan dengan adanya pembelajaran daring. Tidak hanya siswa, guru dan orang tua juga mengalami masalah dengan adanya pembelajaran daring. Telah banyak ditemukan riset yang mengkaji tentang efektifitas dan problematika pembelajaran daring. Penelitian (Mirzon, 2020) mengungkapkan bahwa pembelajaran yang dilakukan selama pandemi kurang efektif. Problematika yang muncul selama pembelajaran daring antara lain motivasi belajar siswa menurun, kurangnya sarana pendukung, gangguan signal dan gangguan teknis lainnya (Anugrahana, 2020). Dalam perspektif guru, pembelajaran daring tidak kalah rumitnya dengan permasalahan yang dihadapi siswa. Salah satu problematika yang dihadapi guru dalam pembelajaran daring adalah penggunaan media pembelajaran daring.

Pembelajaran daring memiliki ketergantungan yang sangat tinggi terhadap media. Media memegang peran kunci dalam pembelajaran daring. Berhasil atau tidaknya pembelajaran daring sebagian besar dipengaruhi oleh penggunaan media (Pujiati \& Yulianto, 2021). Besarnya peranan media dalam pembelajaran daring menuntut seorang guru agar mampu menggunakan media pembelajaran daring dengan baik. Jenis media yang berkaitan erat dengan pembelajaran daring adalah aplikasi berbasis web. Aplikasi ini memungkinkan guru dan siswa dapat belajar dari jarak jauh dengan memanfaatkan jaringan internet. Berdasarkan uraian latar belakang tersebut perlu dilakukan kajian terhadap ekspektasi guru terhadap aplikasi berbasis web dalam kegiatan pembelajaran. Penelitian ini bertujuan untuk mengetahui harapan dan profil kemampuan guru dalam penggunaan aplikasi berbasis web dalam pembelajaran daring. Melalui penelitian ini diharapkan dapat mengukur sejauh mana guru dalam memanfaatkan aplikasi berbasis web 
dalam pembelajaran.

\section{KAJIAN TEORI}

Pembelajaran daring merupakan salah satu model pembelajaran jarak jauh yang dilakukan oleh guru selama pandemi. Maksud dari pembelajaran daring adalah pembelajaran dalam jaringan. Lawan kata dari istilah daring adalah luring (luar jaringan). Kedua istilah ini mulai familiar setelah adanya pandemi Covid19. Pada dasarnya pembelajaran daring memiliki makna yang sama dengan pembelajaran online yaitu pembelajaran jarak jauh yang membutuhkan jaringan internet (Tavangarian, Leypold, Nölting, Röser, \& Voigt, 2004). Pembelajaran dapat dikategorikan daring atau online jika membutuhkan jaringan internet dalam prakteknya. Konsekuensi dengan adanya pembelajaran ini adalah ketergantungan terhadap jaringan internet dan penggunaan aplikasi berbasis web. Hal inilah yang menjadi salah satu kelemahan pembelajaran daring, terkendala jaringan internet (Indahri, 2020). Namun demikian, jika pembelajaran daring dapat di kelola dengan baik berbagai manfaat dapat didapatkan dengan model belajar ini. Menurut pendapat (Bart, Olney, Nichols, \& Herodotou, 2020) pembelajaran daring lebih efektif karena tidak tergantung pada ruang dan waktu. Belajar secara daring dapat dilakukan di mana saja dan kapan saja. Dengan semakin padatnya aktivitas manusia pembelajaran daring dapat menjadi solusi praktis dalam pembelajaran, karena lebih mudah dilakukan tanpa harus bertatap muka secara langsung.

Media pembelajaran merupakan sebuah alat yang digunakan sebagai perantara proses pembelajaran. Media pembelajaran secara umum dikelompokkan menjadi empat yaitu media yang berasal dari teknologi cetak, media yang berasal dari teknologi audio visual, media yang berbasis teknologi komputer dan media gabungan (Sururuddin, Burhanuddin, Zohrani, \& Safitri, 2020). Dengan adanya perkembangan teknologi yang semakin canggih media tidak hanya berbasis cetak, tetapi juga berbasis digital. Media digital semakin berkembang pesat dan banyak diminati oleh berbagai kalangan. Berbagai kreasi dan inovasi terbaru mewarnai perkembangan media digital dalam bidang pembelajaran. Penggunaan platform digital dalam pembelajaran online merupakan contoh konkritnya. Pembelajaran online membutuhkan berbagai macam aplikasi, salah satunya adalah aplikasi berbasis web browser.

Aplikasi berbasis web mulai masif digunakan seiring dengan adanya penggunaan internet yang semakin luas. Aplikasi ini memiliki berbagai keunggulan jika dibandingkan dengan aplikasi yang berbasis desktop (Adani, 2018). Untuk menjalankan aplikasi ini dibutuhkan web server dan browser seperti Chrome, Firefox dan sejenisnya. Selain itu aplikasi ini juga membutuhkan jaringan internet untuk menjalankanya. Aplikasi berbasis web memiliki berbagai macam jenis, diantaranya adalah web media sosial, web sistem informasi, web bisnis, web pencarian, web server, dan web browser. Penggunaan aplikasi berbasis web semakin luas dan dapat dimanfaatkan dalam berbagai bidang kehidupan, salah satunya dapat dimanfaatkan dalam bidang pembelajaran. Beberapa aplikasi yang sering digunakan dalam pembelajaran daring antara lain aplikasi What's App, Google Meet, Zoom, Google Classroom, Zooho, Quizizz, Google Form dan sejenisnya. Untuk menjalankan aplikasi tersebut diperlukan perangkat pendukung seperti Android, Laptop, dan sejenisnya. Salah satu aplikasi berbasis web yang sangat familiar adalah Gmail. Gmail sebagai salah satu aplikasi yang dibuat oleh Google memiliki berbagai fitur yang memungkinkan pengguna untuk mempermudah aktivitas pembelajaran. Beberapa kelebihan aplikasi berbasis web antara lain dapat diakses dari berbagai macam perangkat, tidak membuthkan lisensi, spesifikasi website ringan, dapat digunakandalam berbagai sistem operasi, dan dapat akses kapanpun dan di manapun. Namun 
demikian terdapat juga beberapa kelemahan aplikasi berbasis web, antara lain membutuhkan jaringan internet yang stabil dan rawan terkena hacker jika tidak memiliki sistem keamanan jaringan yang baik.

\section{METODE PENELITIAN}

Penelitian dirancang dalam bentuk penelitian kuantitatif dengan pendekatan deskriptif. Tahapan penelitian meliputi observasi awal, penentuan tema penelitian, penyusunan instrumen, pengumpulan data, analisis data, mendeskripsikan data, menarik kesimpulan dan menyusun rekomendasi penelitian. Pengumpulan data menggunakan survei. Instrumen yang digunakan berupa angket. Selain menggunakan angket peneliti juga melakukan wawancara terbatas untuk memperkuat hasil survei. Subjek penelitian guru sekolah dasar. Jumlah guru yang disurvei sebanyak 15 guru. Lokasi penelitian di SDN 2 Golong, salah satu sekolah dasar di kabupaten Lombok Barat. Indikator yang digunakan untuk mengetahui persepsi guru terhadap penggunaan aplikasi berbasis web dalam pembelajaran selama pandemi dapat terlihat pada Tabel 1. Indikator tersebut kemudian dikembangkan dalam bentuk daftar pertanyaan yang digunakan untuk menyusun angket responden. Data dianalisis menggunakan statistik deskriptif dengan langkah-langkah tabulasi data, persentase data, interpretasi data dan pengambilan kesimpulan.

Tabel 1. Instrumen Angket Responden

\begin{tabular}{ll}
\hline \multicolumn{1}{c}{ Indikator } & \multicolumn{1}{c}{ Pertanyaan } \\
\hline $\begin{array}{l}\text { Intensitas penggunaan aplikasi } \\
\text { web }\end{array}$ & $\begin{array}{l}\text { Apakah bapak ibu pernah menggunakan aplikasi berbasis } \\
\text { web dalam pembelajaran di era pandemi? }\end{array}$ \\
$\begin{array}{l}\text { Urgensi penggunaan aplikasi web } \\
\text { Apakah aplikasi berbasis web penting untuk digunakan } \\
\text { dalam kegiatan pembelajaran di era pandemi? }\end{array}$ \\
$\begin{array}{ll}\text { Kecakapan penggunaan aplikasi } \\
\text { web }\end{array}$ & $\begin{array}{l}\text { Apakah bapak ibu/guru mampu mengoperasikan aplikasi } \\
\text { berbasis web dengan baik dalam pembelajaran di era } \\
\text { pandemi? }\end{array}$ \\
$\begin{array}{l}\text { Kebermanfaatan penggunaan } \\
\text { aplikasi web } \\
\text { Kebutuhan terhadap pelatihan } \\
\text { penggunaan aplikasi web }\end{array}$ & $\begin{array}{l}\text { Apakah dengan menggunakan aplikasi berbasis web } \\
\text { pembelajaran di era pandemi menjadi lebih mudah? } \\
\text { Apakah bapak/ibu guru membutuhkan pelatihan khusus } \\
\text { terhadap penggunaan aplikasi berbasis web? }\end{array}$ \\
\hline
\end{tabular}

\section{HASIL DAN PEMBAHASAN}

Ekspektasi guru terhadap penggunaan aplikasi berbasis web dalam pembelajaran selama pandemi dapat terlihat dari lima indikator persepsi yang telah dikembangkan. Terdapat lima indikator yang dikembangkan untuk gunakan dalam menjaring data, antara lain: intensitas penggunaan aplikasi web, urgensi penggunaan aplikasi web, kecakapan penggunaan aplikasi web, kebermanfaatan penggunaan aplikasi web dan kebutuhan guru terhadap pelatihan penggunaan aplikasi web. Lima indikaor utama yang menggambarkan ekspektasi guru dapat diuraikan sebagai berikut.

\section{Intensitas Penggunaan Aplikasi Berbasis Web}




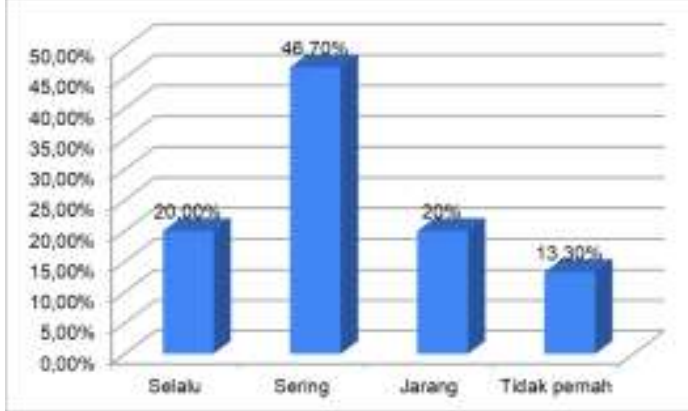

\section{Gambar 1. Intensitas Penggunaan Aplikasi Web}

Diagram pada gambar 1 menggambarkan tentang seberapa sering guru menggunakan aplikasi berbasis web selama pandemi. Berdasarkan gambar tersebut dapat diketahui bahwa jumlah guru yang selalu menggunakan aplikasi berbasis dalam pembelajaran selama pandemi sebesar $20 \%$ dari 15 guru yang disurvei. Jumlah guru yang mengaku sering menggunakan sebanyak $46,70 \%$, sedangkan yang jarang menggunakan sebanyak 20\%. Berdasarkan gambar tersebut juga ditemukan sebanyak 13,30\% guru yang mengaku tidak pernah menggunakan aplikasi berbasis web dalam pembelajaran selama pandemi. Hal ini menunjukkan bahwa pemanfaatan aplikasi berbasis web oleh guru dalam pembelajaran di masa pandemi belum merata.

\section{Urgensi Penggunaan Aplikasi Web}

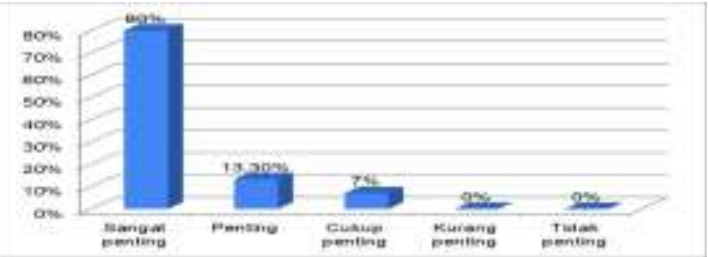

Gambar 2. Urgensi Penggunaan Aplikasi Web

Diagram pada gambar 2 menjawab cukup penting. Data ini menggambarkan persepsi guru terkait dengan menunjukkan bahwa sebagian besar guru telah seberapa penting penggunaan aplikasi berbasis memahami betapa pentingnya penggunaan web dalam pembelajaran selama pandemi. aplikasi berbasis web dalam menunjang Hasil survei terkait dengan urgensi penggunaan aplikasi berbasis web menunjukkan bahwa $80 \%$ guru menganggap sangat penting, 13,30 pentingdan $7 \%$ kegiatan pembelajaran di era pandemi.

\section{Kecakapan Penggunaan Aplikasi Web}

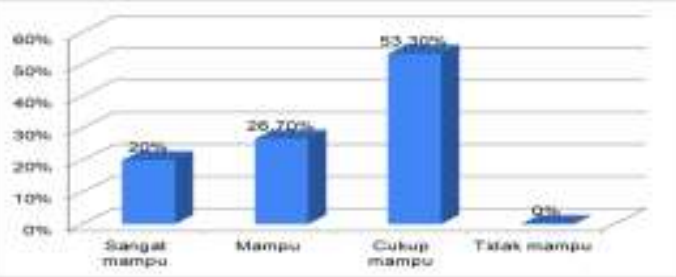

Gambar 3. Kecakapan guru dalam penggunaan aplikasi web 


\section{PRIMARY: JURNAL PENDIDIKAN GURU SEKOLAH DASAR VOLUME 10 NOMOR 5 OKTOBER 2021 \\ ISSN : 2303-1514 | E-ISSN : 2598-5949 \\ DOI : http://dx.doi.org/10.33578/jpfkip.v10i5.8528 \\ https://primary.ejournal.unri.ac.id/index.php/JPFKIP}

Diagram pada gambar 3 menggambarkan kemampuan guru dalam menggunakan aplikasi berbasis web dalam pembelajaran. Berdasarkan gambar tersebut dapat diketahui sebanyak 53,30\% guru menjawab cukup mampu, sedangkan yang menjawab mampu sebesar $26,70 \%$ dan menjawab sangat mampu sebanyak $20 \%$. Data ini menunjukkan bahwa sebagian besar guru masih merasa ragu untuk menjawab mampu.
Hal ini mengindikasikan bahwa banyak guru yang masih mengalami hambatan dalam penggunaan aplikasi web dalam pembelajaran. Hanya $20 \%$ guru yang merasa yakin dapat menggunakan aplikasi berbasis web dengan baik dalam pembelajaran.

\section{Kebermanfaatan penggunaan aplikasi web}

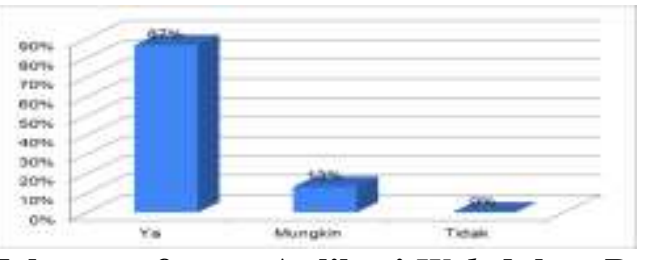

Gambar 4. Kebermanfaatan Aplikasi Web dalam Pembelajaran

Diagram pada gambar 4 masih ragu. Data ini menunjukkan bahwa menggambarkan persepsi guru terkait dengan masih ada sebagian guru yang belum manfaat yang dirasakan guru dalam menunjang sepenuhnya merasakan kemudahan yang kegiatan pembelajaran di era pandemi dengan ditawarkan oleh penggunaan aplikasi berbasis menggunakan aplikasi berbasis web. Hasil srurvei menunjukkan bahwa sebanyak $87 \%$ guru telah merasakan manfaat penggunaan aplikasi tersebut, sedangkan $13 \%$ menyatakan

\section{Kebutuhan terhadap pelatihan penggunaan aplikasi $w e b$}

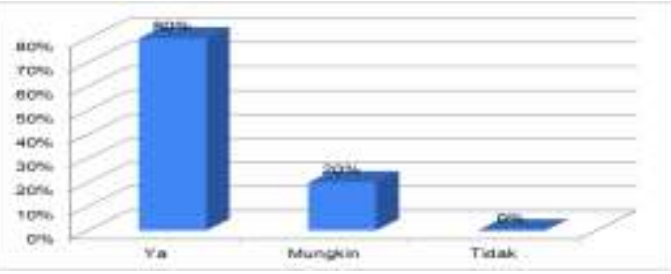

\section{Gambar 5. Kebutuhan Guru Terhadap Pelatihan}

Diagram pada gambar 5 menunjukkan bahwa sebagian besar guru merasa sangat membutuhkan pelatihan khusus terkait dengan penggunaan aplikasi berbasis web dalam pembelajaran. Dari 15 guru yang disurvei setidaknya $80 \%$ menjawab sangat butuh, sedangkan $20 \%$ masih ragu. Data ini menggambarkan bahwa para guru sesungguhnya membutuhkan pelatihan khusus untuk meningkatkan kompetensinya dalam penggunaan aplikasi sebagai media pembelajaran di masa pandemi, terutama dalam pembelajaran daring.

Berdasarkan hasil penelitian dapat diketahui bahwa sebagian besar guru telah menggunakan aplikasi berbasis web dalam pembelajaran. Hal ini dapat diperkuat dengan data yang menunjukkan bahwa sebagian besar guru telah sadar terkait dengan pentingnya penggunaan aplikasi berbasis web sebagai media pembelajaran. Sebagian besar guru juga telah merasakan manfaat yang diperoleh dengan menggunakan aplikasi berbasis web 
dalam pembelajaran. Namun demikian aplikasi yang digunakan guru masih sangat terbatas, hanya sebatas WhatsApp Group. Kemampuan guru dalam penggunaan aplikasi berbasis web yang lain masih terbatas. Kondisi semacam ini memicu terjadinya hambatan dalam proses pembelajaran, karena tidak ada variasi dalam model pembelajaran. Hambatan ini disebut dengan hambatan pedagogis. Menurut (Adi, Martono, \& Sudarno, 2021) hambatan pedagogis merupakan jenis hambatan yang dialami oleh guru karena kurangnya inovasi dan keterbatasan kemampuan dalam menggunakan media pembelajaran yang inovatif. Salah satu penyebabnya adalah keterbatasan guru dalam penguasaan teknologi pembelajaran yang berbasis e-learning. Hal ini sesuai dengan pernyataan (Indahri, 2020) bahwa guru dalam menghadapi pembelajaran di era pandemi sangat membutuhkan pendampingan, pelatihan, dan pengarahan teknis. Hal ini sangat penting dilakukan dalam rangka meningkatkan kompetensi literasi digital para guru.

\section{SIMPULAN DAN REKOMENDASI}

Berdasarkan uraian dalam pembahasan dapat disimpulkan bahwa pada dasarnya guru telah menggunakan aplikasi berbasis web tetapi hanya terbatas pada WhatssApp Group. Kecakapan guru dalam penggunaan aplikasi berbasis masih terbatas. Guru telah menyadari bahwa penggunaan aplikasi berbasis web sangat penting untuk dikuasai dalam rangka menunjang kegiatan pembelajaran daring selama pandemi. Guru berharap mendapatkan pelatihan terhadap penggunaan aplikasi berbasis web agar media pembelajaran yang digunakan lebih bervariasi untuk mengurangi rasa bosan siswa dalam belajar daring.

Berdasarkan simpulan di atas terdapat beberapa saran yang dapat diberikan, antara lain: Pertama, perlunya pelatihan dan pendampingan terhadap guru terkait dengan penggunaan media pembelajaran daring oleh pemerintah maupun pihak-pihak yang terkait dengan pendidikan di sekolah dasar. Kedua, para guru hendaknya selalu berusaha dan belajar dengan kebaruan-kebaruan aplikasi yang dapat manfaatkan sebagai media pembelajaran.

\section{DAFTAR PUSTAKA}

Abidah, A., Hidaayatullaah, H. N., Simamora, R. M., Fehabutar, D., \& Mutakinati, L. (2020). The Impact of Covid-19 to Indonesian Education and Its Relation to the Philosophy of "Merdeka Belajar." Studies in Philosophy of Science and Education, 1(1), 38-49. https://doi.org/10.46627/sipose.v1i1.9

Adani, M. R. (2018). Jenis Aplikasi Berbasis Web Beserta Contoh Penerapannya. Retrieved from Sekawan Media Informatika website: https://www.sekawanmedia.co.id/aplik asi-berbasis-web/

Adi, P. W., Martono, T., \& Sudarno, S. (2021). Learning Failures and Barriers in Schools During a Pandemic at Indonesia: A Literature Review. Duconomics Sci-Meet (Education \& Economics Science Meet), 1(085230975597), 160-165. https://doi.org/10.37010/duconomics.v 1.5436

Anugrahana, A. (2020). Hambatan, Solusi dan Harapan: Pembelajaran Daring Selama Masa Pandemi Covid-19 Oleh Guru Sekolah Dasar. Jurnal Pendidikan Dan Kebudayaan, 10(3), 282-289.

Bart, R., Olney, T., Nichols, M., \& Herodotou, C. (2020). Effective usage of learning analytics: what do practitioners want and where should distance learning institutions be going? Open Learning: The Journal of Open, Distance and eLearning, 35(2), 178-195. https://doi.org/10.1080/02680513.2019 .1690441

Indahri, Y. (2020). Permasalahan Pembelajaran Jarak Jauh Di Era Pandemi. Pusat Penelitian Badan 
Keahlian DPR R, 19, 13-18. Retrieved from

https://berkas.dpr.go.id/puslit/files/info _singkat/Info Singkat-XII-12-II-P3DIJuni-2020-201.pdf

Komalawati, R. (2020). Manajemen Pelaksanaan Tes Diagnostik Awal Untuk Mengidentifikasi Learning Loss. Edupena, 01(02), 135-148.

Mirzon, D. J. D. A. D. A. (2020). Efektifitas WhatsApp Sebagai Media Belajar Daring. Jurnal Basicedu, 4(4), 775783.

https://doi.org/10.31004/basicedu.v4i4. 445

Pradana, L. N. (2016). E-Learning Pada Pembelajaran Geometri Dan Hubungannya Dengan Kecerdasan Majemuk. Posiding Seminar Nasioanal "Menjadi Guru Inspirator," (April), 365-374. Purwokerto: Universitas Muhammadiyah Purwokerto.

Pujiati, D., \& Yulianto, D. (2021). Analisis Media Pembelajaran Anak Usia Dini Berbasis Teknologi Masa Pandemi Covid-19. Efektor, 8(1), 45-52. https://doi.org/10.29407/e.v8i1.15857
Sururuddin, M., Burhanuddin, Zohrani, \& Safitri, A. D. (2020). Pengembangan Media Audio Visual Berbasis Kearifan Lokal Pada Tema 1 Indahnya Kebersamaan Kelas IV SDN Tahun Pelajaran 2019/2020. Jurnal DIDIKA : Wahana Ilmiah Pendidikan Dasar, VI(1), 139-147.

Tavangarian, D., Leypold, M. E., Nölting, K., Röser, M., \& Voigt, D. (2004). Is eLearning the Solution for Individual Learning? Electronic Journal of ELearning, 2(2), 273-280. Retrieved from http://wwwra.informatik.unirostock.de

Widodo, A., \& Nursaptini, N. (2020). Merdeka belajar dalam pandemi: Persepsi mahasiswa terhadap pembelajaran jarak jauh berbasis mobile. Jurnal Pembangunan Pendidikan: Fondasi Dan Aplikasi, 8(2), 86-96. https://doi.org/10.21831/jppfa.v8i2.35 747 